\title{
Uma propriedade "esquecida" sobre área de regiões poligonais
}

\author{
Roberto Ribeiro Paterlini(D)
}

\section{Resumo}

Apresentamos neste texto uma demonstração de que a área de uma região poligonal não depende da forma como ela é repartida em regiões mais elementares. Essa propriedade faz parte da construção do conceito de área em Geometria Elementar, mas nem sempre é destacada nos livros didáticos.

Palavras-chave: Geometria; áreas; áreas de polígonos.

\begin{abstract}
We present in this text a demonstration that the area of a polygonal region does not depend as it is broken down into more elementary regions. This property is part of the construction of the concept of area in Elementary Geometry, but is not always highlighted in textbooks.
\end{abstract}

Keywords: Geometry; area; polygonal area.

\section{Introdução}

É de conhecimento comum dos estudantes o seguinte método para calcular a área de uma região poligonal: repartimos a região dada em regiões mais elementares, cujas áreas sabemos calcular, e em seguida somamos essas áreas. Isso nos fornece um método geral para o cálculo da área dessas regiões do plano.

Do ponto de vista formal esse método exige uma resposta positiva à seguinte questão: se uma região poligonal for repartida em regiões triangulares de formas diferentes, a soma das áreas sempre resultará no mesmo valor? 

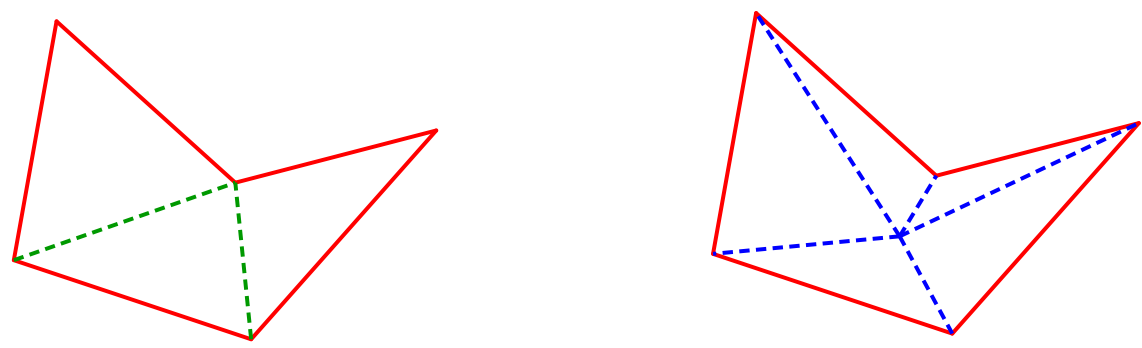

Figura 1: Região poligonal com duas repartições diferentes usando triângulos.

A Figura 1 mostra um exemplo de região pentagonal com duas triangulações diferentes. Veremos que são iguais as somas das áreas dos triângulos em cada triangulação.

Os livros didáticos não trazem, em geral, essa observação. Acredito que o motivo seja não acumular um excesso de resultados técnicos no texto, ficando por conta do professor destacar tal propriedade. Faremos mais abaixo algumas observações adicionais sobre essa questão.

Vejamos como se pode argumentar que a área não depende da forma como é repartida a região. Consideramos apenas repartições em triângulos, pois se usarmos retângulos, paralelogramos, trapézios ou outras figuras elementares, essas figuras sempre podem ser repartidas, por sua vez, em triângulos.

\section{Um pouco de formalização}

Uma região triangular é o conjunto de pontos formado por um triângulo e seu interior. Os lados da região são os lados do triângulo, e os vértices da região são os vértices do triângulo.

Um complexo triangular é a reunião de uma quantidade finita e não nula de regiões triangulares em um mesmo plano, de forma que esteja satisfeita a seguinte condição: se duas regiões triangulares intersectam-se, elas o fazem em um vértice comum ou em um lado comum.

Em particular, em um complexo triangular, duas regiões triangulares quaisquer não têm pontos interiores em comum.

Vemos que um complexo triangular $K$ consiste de dois elementos: uma coleção $T=\left\{T_{1}, T_{2}, \ldots, T_{n}\right\}$ de regiões triangulares satisfazendo à condição dada acima, e o conjunto $R$ de pontos do plano que é a reunião dessas regiões. Podemos usar a notação $K=(R, T)$ para indicar um complexo triangular. Duas coleções diferentes $T$ e $T^{\prime}$ de regiões triangulares podem definir o mesmo conjunto $R$ de pontos, mas então temos dois complexos diferentes $K=(R, T)$ e $K^{\prime}=\left(R, T^{\prime}\right)$. Na Figura 1 vemos um exemplo de tal situação.

Observamos agora que podemos definir área de complexos triangulares. Dado um complexo triangular $K$, sua área $a(K)$ é um número real positivo que satisfaz às três condições seguintes: 
Ai) Se dois triângulos são congruentes, as regiões triangulares por eles definidas têm a mesma área.

Aii) Se dois complexos $K_{1}$ e $K_{2}$ não se intersectam ou se sua interseção consiste apenas de vértices e lados de suas triangulações, a área da união $K_{1} \cup K_{2}$ é a soma $a\left(\mathcal{K}_{1}\right)+a\left(K_{2}\right)$.

Aiii) A área do quadrado de lado 1 é 1.

A existência da área de complexos triangulares pode ser demonstrada. Uma forma elementar (mas não simples) de fazer isso está exposta no Capítulo 14 de [3], a partir da página 168. Confira também [5], página 63 e seguintes.

Para evitar detalhes técnicos, a maioria dos livros didáticos de Geometria Euclidiana assume a existência da área como um postulado. Como se tratam de noções comuns, parece que os estudantes não têm dificuldade em aceitar as condições Ai), Aii) e Aiii) mediante uma boa explicação do professor.

Estabelecida a existência da área (por construção ou por postulação), costuma-se seguir a seguinte sequência dedutiva, cujos detalhes podem ser encontrados em livros de Geometria Elementar (confira, por exemplo, [4], a partir da página 205):

a) Demonstrar que a área de qualquer quadrado de lado $a$ é $a^{2}$, para todo número real $a$ positivo.

b) Demonstrar que a área de qualquer retângulo de lados $a$ e $b$ é $a b$.

c) Demonstrar que, em qualquer triângulo, é invariante o produto de um lado pela altura respectiva, e que sua área é a metade desse valor.

d) Demonstrar que, em qualquer paralelogramo, é invariante o produto de um lado pela altura correspondente, e que sua área é esse valor.

e) Demonstrar que a área de um trapézio qualquer é o produto da semissoma das bases pela distância entre elas.

Além disso vemos que, em geral, a área de um complexo triangular $K=(R, T)$, em que $T=$ $\left\{T_{1}, T_{2}, \ldots, T_{n}\right\}$, pode ser calculada por

$$
a(K)=a\left(T_{1}\right)+a\left(T_{2}\right)+\cdots+a\left(T_{n}\right)
$$

Entretanto, queremos um pouco mais. Desejamos que a área de um complexo triangular não dependa da particular triangulação. Essa propriedade também costuma ser adotada como postulado ao se assumir que a relação região $\rightarrow$ área é uma função. Entendemos que aqui a aceitação dos estudantes pode não ser tão tranquila. O que faremos é apresentar um argumento para verificar essa unicidade.

\section{Demonstração da propriedade}

Consideremos dois complexos triangulares $K=(R, T)$ e $K^{\prime}=\left(R, T^{\prime}\right)$, que definem a mesma região $R$ do plano, mas com duas repartições diferentes em regiões triangulares, digamos, $T=$ $\left\{T_{1}, T_{2}, \ldots, T_{n}\right\}$ e $T^{\prime}=\left\{T_{1}^{\prime}, T_{2}^{\prime}, \ldots, T_{m}^{\prime}\right\}$. Sabemos que

$$
a(K)=a\left(T_{1}\right)+a\left(T_{2}\right)+\cdots+a\left(T_{n}\right)
$$


e

$$
a\left(K^{\prime}\right)=a\left(T_{1}^{\prime}\right)+a\left(T_{2}^{\prime}\right)+\cdots+a\left(T_{m}^{\prime}\right)
$$

Queremos provar que esses dois números são iguais. Para isso consideremos o conjunto $C$ formado pelos seguintes pontos: a) todos os vértices dos triângulos das duas repartições; b) todas as interseções de lados de triângulos das duas repartições, lados cujas retas suportes sejam diferentes. $\mathrm{O}$ conjunto $C$ é finito. Escolhemos no plano uma reta $\ell$, e consideremos as retas $\ell_{1}, \ell_{2}, \ell_{3}, \ldots, \ell_{p}$ paralelas a $\ell$ e passando por todos os pontos de $C$. Vemos uma ilustração na Figura 2, na qual a região tem duas repartições em regiões triangulares, uma marcada com linhas verdes interrompidas e a outra com linhas azuis interrompidas.

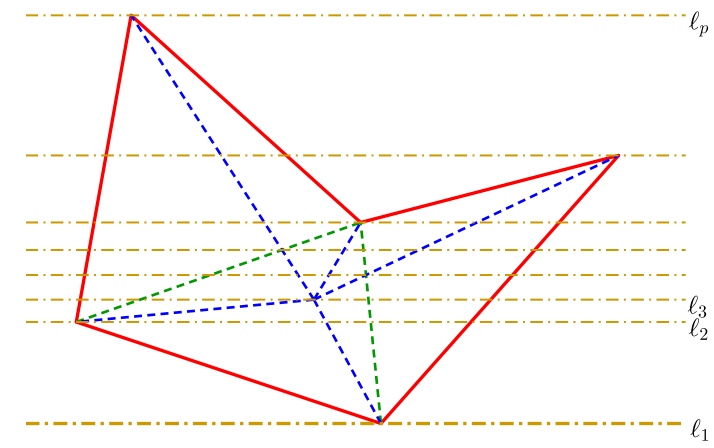

Figura 2: Dissecando uma região com duas repartições.

Considerando os lados dos triângulos das duas repartições e os segmentos que eles determinam nas retas $\ell_{i}$ vemos que $R$ fica repartido em regiões triangulares e trapezoidais. Cada trapézio pode ser repartido em dois triângulos com uma de suas diagonais, de forma que $R$ fica repartido com essas regiões triangulares, que chamamos de $T_{i}^{\prime \prime}, 1 \leq i \leq s$. Consideremos o complexo triangular $K^{\prime \prime}=\left(R, T^{\prime \prime}\right)$, cuja área é o número

$$
a\left(K^{\prime \prime}\right)=a\left(T_{1}^{\prime \prime}\right)+a\left(T_{2}^{\prime \prime}\right)+\cdots+a\left(T_{s}^{\prime \prime}\right) \quad(* * *)
$$

Notemos agora que cada região triangular $T_{i}$ é a reunião de regiões $T_{j}^{\prime \prime}$, sem repetição, e as fórmulas $\left(^{*}\right)$ e $(* * *)$ dizem-nos que $a(K)=a\left(K^{\prime \prime}\right)$. Do mesmo modo cada região triangular $T_{i}^{\prime}$ é a reunião de regiões $T_{j}^{\prime \prime}$, sem repetição, e as fórmulas $\left({ }^{* *}\right)$ e $\left({ }^{* *}\right)$ dizem-nos que $a\left(K^{\prime}\right)=a\left(K^{\prime \prime}\right)$.

Portanto $a(K)=a\left(K^{\prime}\right)$, e vemos que a área de um complexo triangular não depende da particular triangulação.

Observamos que um complexo triangular pode ter várias partes, chamadas subregiões conexas. Na Figura 2 representamos um complexo com apenas uma parte. Entretanto o argumento mantém-se também para esses complexos. 


\section{Como ficam as regiões poligonais?}

Todo polígono simples (sem autointerseções), convexo ou não, determina no plano uma região limitada, chamada interior do polígono. O polígono e seu interior formam um conjunto que chamamos de região poligonal. Uma demonstração desse resultado pode ser lida em [1], a partir da página 103.

Toda região poligonal é um complexo triangular. Uma demonstração dessa propriedade pode ser vista em [2], pág. 35. Juntando esse resultado com o que comentamos anteriormente vemos que a área de uma região poligonal qualquer não depende da forma com que é repartida em regiões mais elementares.

\section{Relembrando a fórmula do "cadarço de sapato"}

Dado um polígono $A_{1} A_{2} A_{3} \ldots A_{n}$ consideremos em seu plano um sistema de coordenadas cartesianas Oxy. Sejam $A_{i}=\left(x_{i}, y_{i}\right)$ as coordenadas dos pontos $A_{i}, 1 \leq i \leq n$. Então o dobro de sua área é o valor absoluto do número

$\left|\begin{array}{llllll}x_{1} & x_{2} & x_{3} & \ldots & x_{n} & x_{1} \\ y_{1} & y_{2} & y_{3} & \ldots & y_{n} & y_{1}\end{array}\right|=x_{1} y_{2}+x_{2} y_{3}+x_{3} y_{4}+\cdots+x_{n} y_{1}-x_{2} y_{1}-x_{3} y_{2}-x_{4} y_{3}-\ldots-x_{1} y_{n}$

Essa é a chamada fórmula do cadarço de sapato, também conhecida como fórmula de Gauss. A demonstração dessa fórmula usa triangulações da região poligonal, de modo que ela não fornece um novo valor. Mais detalhes podem ser lidos em [6] .

Reforçamos que qualquer fórmula ou método de cálculo da área de uma região poligonal parte, explícita ou implicitamente, da fórmula (1), e assim a área terá sempre o mesmo valor.

\section{Referências}

[1] André, L. e Aguiar, R. "Caracterizações de convexidade para polígonos simples. Professor de Matemática Online," v.7, n.1, 2019, págs 95 a 121. Disponível em <http://pmo.sbm.org.br/wp-content/uploads/sites/16/dlm_uploads/2019/05/atualiz.art8_ vol7_2019_PMO_SBM-1-1.pdf> Acesso em: 7 de janeiro de 2020.

[2] Lima, E. L. "Qual é a soma dos ângulos (internos e externos) de um polígono (convexo ou não)? Revista do Professor de Matemática, " n. 19, págs 31 a 38. São Paulo, Sociedade Brasileira de Matemática, 1991.

[3] Moise, E. E. Elementary Geometry from an advanced standpoint. Reading, Massachusetts, Addison-Wesley Publishing Company, 1974.

[4] Paterlini, R. R. Geometria Elementar, gênese e desenvolvimento. Disponível em https://www. dm.ufscar.br/ ptlini/livros/livro_geo.html Consultado em 04 de março de 2019.

[5] Shiga, K. e Sunada, T. A Mathematical Gift, III: The interplay between topology, functions, geometry and algebra. Providence, Estados Unidos, American Mathematical Society, 2005. 
[6] Victor, C. A. S. “Área de um polígono. Revista do Professor de Matemática," n. 35, págs 28 a 32. São Paulo, Sociedade Brasileira de Matemática, 1997.

Roberto Ribeiro Paterlini Universidade Federal de São Carlos <roberto@dm.ufscar.br>

Recebido: $02 / 01 / 2020$

Publicado: 27/03/2020 